v. Lucanus und v. Quistorp über Fluggeschwindigkeit und Ortssinn. Herr v. Quistorp beobachtete für Krähen eine Geschwindigkeit von $13 / 4-2 \mathrm{~km}$ für die Minute, Herr R örig erwähnt ein selbstbeobachtetes Beispiel, woraus hervorgeht, dafs Säugetiere einen ausgesprochenen Ortssinn haben, der bei Vögeln wohl mehr durch die Gesichtsorientierung ersetzt wird. Herr v. Lucan us glaubt nach seinen Beobachtungen, dafs selbst Schwalben sich bei ihren Jagdflügen nur wenige hundert Meter vom Neste zu entfernen pflegen, sie finden sich daher, gewaltsam weiter entfernt, nur schwer wieder nach Hause. Die Ausstellung weiterer exakter Experimente ist sehr erwünscht.

Heinroth.

\title{
Bericht über die Februarsitzung 1907.
}

Verhandelt Berlin, Montag, den 4. Februar, abends 8 Uhr im Architekten-Vereinshause, Wilhelmstr. 92.

Anwesend die Herren Heck, Reichenow, Deditius, Rörig, Ehmcke, v. Treskow, Paeske, Selmons, Jung, Haase, Grunack, Neunzig, Schiller, v. Lucanus, Schalow, 0. Neumann, Heinroth.

Als Gäste die Herren P. und K. Ko the und Frau Hein roth.

Vorsitzender Herr Heck, Schriftführer Herr Heinroth.

Herr Reichenow bespricht die eingegangene Literatur und weist besonders hin auf eine Abhandlung von W. Be ebe im Auk, betreffend das biologische Verhalten soeben dem Ei entschlüpfter Urinator imber. Es geht aus dem Bericht hervor, dafs diese Tiere, wie die übrigen Nestflüchter, eine grofse Zahl von Instinkthandlungen mit auf die Welt bringen. Gelegentlich dieser Besprechung wird die Frage aufgeworfen, weshalb wohl die Podicipes stets ihrem Magen Federn einverleiben und ob die Dunenjungen diese von ihren Eltern mit dem Futter vorgelegt bekommen. Die Herren Heck, Heinroth, O. Neumann und Schalow beteiligen sich an der Diskussion.

Herr 0 . Neumann bespricht hierauf die kurzschwänzigen Glanzstare, Lamprocolius, und ihre Formenkreise, wobei er das entsprechende Material vorlegt. Auffallend ist dabei, dafs bei der Chloropterus-Gruppe sich vor der Mauser sämtliche Federn in der Weise verändern, dafs sie den Glanz völlig verlieren und bleifarbig, ja bei einigen Formen sogar gelb werden. Bei den Chalybaeus-Formen erleidet dagegen nur das Grofsgefieder diese Veränderung. Der Vortragende bespricht die Zugehörigkeit verschiedener Glanzstararten zu diesen beiden Gruppen bezüglich Formenkreisen. Die Herren Reichenow, Heck und Schalow beteiligen sich an der anschliefsenden Diskussion und weisen darauf hin, dafs eine mikroskopische Untersuchung am besten über diese eigenartige Federveränderung Aufschlufs geben könne. Herr Heinroth erinnert an das leichtzubeobachtende Braun- 
werden des glänzenden Grosisgefieders bei Cairina moschata vor der Mauser.

Herr Reichenow legt hierauf europäjsch-sibirische Kleiberarten vor und bespricht dieselben. : Insbesondere weist der Vortragende an einer gröfseren . Reihe von Bälgen darauf hin, dafs die Kleiber des nördlichen Deutschlands sich von südeuropäischen und anscheinend auch . westdeutschen durch blasseren und unreineren Ton der Unterseite, der bei den südlichen reiner und. lebhafter. ockergelb. ist, unterscheiden. Die erstgenannte Form; die als var. sordida zu bezeichnen ist, liegt dem Redner aus der Mark, Mecklenburg, Pommern, Schlesien, West- und Ostpreussen vor, die lebhafter und reiner gefärbte Form aus Nieder-Österreich, Ungarn, Rumänien und Kurbessen. - In einer von Herrn C. Wa che im Altai-Gebiet. (Telezky-See) zusammengebrachten Sammlung, die Herr Dr. Biedermann-Imh o of in Eutin dem zoologischen Museum in Berlin zum Geschenk gemacht, konnte der. Vortragende einen zierlichen Kleiber feststellen, der anscheinend einer noch unbeschriebenen Form angehört. Sitta biedermanni, wie der Vogel benaunt wird, steht augenscheinlich der $S$. albifrons Tacz. am nächsten, hat breites weilses Stirnband, deutlichen weifsen Augenbrauenstrich und nur wenig. Rotbraun auf den Weichen, ist aber wesentlich kleiner und hat namentlich viel zierlicheren Schnabel. Flügel $76-80$, Schnabel $15 \mathrm{~mm}$.

Herr Heinroth legt den Schwanz des Wollhals-Storches vor und zeigt an ihm die merkwürdige Erscheinung, dafs die mittleren Steuerfedern stark verkürzt sind und funktionell an ihre Stelle die verlängerten und harten Unterschwanzdecken treten:

Herr Schalow legt eine Anzahl Exemplare von Saxicola pleschanka (Lepech.) vor, welche von Dr. Merzbacher im Tiën-schan gesammelt wurden. Darunter befindet sich ein im September erlegtes Männchen, welches vollkommen dem Vogel gléicht; iler von Allan 0. Hume - (Lahore to Yarkand, 1873, p. 206; Taf. 13) als Srxicola hendersoni beschrieben und abgebildet wurde." Die mehrfach angezweifelte Synonymie der beiden vorgenannten Arten ist dadurch endgültig sichergestellt. Ob die von Dr. Abbott bei Kargil, Kaschmir, gesammelten Steinschmätzer, welche von Richmond (Pr. U. St. Nat: Mus. 1896 p. 480) als Saxicola pleschanka, aber mit einem Fragezeichen, aufgeführt werden, zu dieser genannten Art gehören, ist sehr zweifelhaft. Jedenfalls sind es nach den 1. c. gegebenen Messungen viel kleinere Vögel. Vielleicht ist die Kaschmir-Form abzutrennen und das Vorkommen von S. pleschanka in Indien auf Gilgit, wo die .Art zur Brutzeit gesammelt wurde, beschränkt:

Herr Reichenow teilt mit, dals neuerdings Saxicola leucorhoa auf Helgoland erlegt sei.

Heinroth. 